\title{
TERRITÓRIOS URBANOS, REDES SOCIAIS E MEMÓRIA COLETIVA: A CIDADE NARRADA E (RE)INVENTADA SOB UMA PERSPECTIVA GERACIONAL
}

\author{
Rojane Brum Nunes ${ }^{1}$
}

\section{O deslocamento Centro-periferia e a construção de um problema de pesquisa}

A presença cotidiana de grupos de aposentados no Centro da cidade, constatada através dos meus próprios deslocamentos nesse espaço - também evocada em conversas com diferentes citadinos, em espaços sociais diversos - assim como a minha prática docente em uma escola de periferia, que implicou um itinerário urbano no sentido Centro-periferia, levaram-me a construir um "potencial de estranhamento" (Velho, 1994) acerca dos diferentes níveis de sentido construídos acerca desse espaço urbano.

A partir dessa confluência de fatores, delineou-se um problema de pesquisa motivado pela busca em apreender as diferentes feições da dinâmica urbana, no qual a Antropologia passou a fazer parte como "uma postura de conhecimento" e como um "questionamento teórico", trazendo o "diferente", tomado aqui como os grupos de aposentados que freqüentam cotidianamente o Centro da cidade de Santa Maria, para a "lógica racional e ordenadora da ciência" (Peirano, 1991: 236).

O objetivo da referida pesquisa, cujos dados, referenciais teóricos e conclusões, serão revisitados neste texto, foi a realização de um estudo antropológico acerca dos significados e das apropriações de espaços urbanos no Centro da cidade, engendrados por esses atores sociais, transformando esses "espaços praticados" (De Certeau, 1994) em territórios de sociabilidade. Por outro lado, buscou-se apreender as suas "estratégias e táticas cotidianas" (Goffman, 1973), a fim de restabelecerem a continuidade na duração social, (re)configurando as suas identidades e pertencimentos, apesar da ruptura com o mundo do trabalho, advinda do processo de aposentadoria. $^{2}$

A pesquisa consistiu no desenvolvimento de uma "etnografia da duração" seguindo a proposta cunhada pelas antropólogas Cornelia Eckert e Ana Luiza Carvalho da Rocha (2005). As referidas autoras, em seus estudos sobre memória e ritmos temporais, se apóiam nas

\footnotetext{
${ }^{1}$ Universidade Aberta do Brasil/Universidade Federal de Pelotas

2 Trata-se da dissertação de mestrado "A “Boca”, a "Esquina” e o "Recanto": sociabilidade, cotidiano e memória entre aposentados habitués do Centro de Santa Maria, RS, Brasil”, desenvolvida junto ao Programa de Pós-Graduação em Antropologia Social da Universidade Federal do Rio Grande do Sul, sob orientação da Prof ${ }^{a}$. Dra ${ }^{\text {a }}$ Cornelia Eckert, defendida em 2010.
} 
contribuições teóricas de Gastón Bachelard (1994), Gilbert Durand (1997), George Simmel (1983), entre outros, para conceber a cidade enquanto um "objeto temporal”, e, a produção do fenômeno urbano como parte do "trajeto antropológico" da humanidade, o qual consiste no "produto das acomodações das pulsões subjetivas humanas às intimações do seu meio cósmico e social" (Durand, 1997:41).

Sob esse enfoque, o espaço urbano é considerado enquanto expressão de uma "fantástica transcendental", na qual se situa o fenômeno da memória que permite aos seus habitantes "remontarem o tempo" e "perenizarem as suas ações no mundo" (Eckert e Rocha, 1998:251), de modo que narrar a cidade em sua duração, é apreender-se ao ritmo de suas estruturas espaciais nas sobreposições temporais vividas por seus habitantes.

A “etnografia da duração", por sua vez, busca apreender nas narrativas dos atores sociais, a configuração do tempo vivido e pensado, na medida em que este dimensiona a memória coletiva e os ritmos temporais que configuram a cidade, desvelando desse modo, as relações entre tempo, imagem e memória, modeladas nas narrativas e trajetórias sociais dos grupos e indivíduos, assim como a relação que estes constroem com a cidade/territórios através de um movimento de suas memórias no tempo.

Nesse sentido, "etnografar a duração" implica ao etnógrafo, o "desafio da recondução do ser-no-tempo dos indivíduos e/ou grupos por ele pesquisados", considerando "as questões ordinárias dos habitantes das grandes cidades, na ordem do vivido, para atingir a capacidade de 'contar' suas estórias com a ajuda desse tempo" (Eckert e Rocha, 2009:116).

Daí a importância da "etnografia de rua" (Eckert e Rocha, 2005), do deslocamento sistemático do antropólogo pela cidade, observando e participando da vida cotidiana no âmbito da rua, em seus fragmentos e micro-eventos, possibilita observar e compreender os atores sociais em sua ambiência cotidiana, vinculando as imagens urbanas a uma trajetória social/individual que faz parte do "trajeto antropológico da humanidade".

A adesão a práticas de sociabilidade em um espaço público denotou a vocação da cidade estudada para disponibilizar espaços e equipamentos urbanos a serem apropriados por citadinos em suas diferentes motivações e condições sociais.

O município de Santa Maria, constantemente evocado enquanto a "cidade coração do Rio Grande”, em decorrência da sua localização na Depressão Central do estado do Rio Grande do Sul, encontra-se a 290 quilômetros de sua capital, Porto Alegre. A sua população total é de 349.424 habitantes, cuja população urbana é de 299.143, sendo que desse total, 
8.792 são homens que possuem acima de 65 anos de idade, o que equivale a 2,93\% dessa população (IBGE, 2009). ${ }^{3}$

No decorrer da sua história social, esse município foi atravessado por elementos estruturantes da modernidade e por projetos estimuladores de um "processo civilizador" (Elias, 1994) com vistas ao desenvolvimento regional. Entre tais projetos, destaca-se a implantação da Viação Férrea, das forças armadas (Exército, Aeronáutica), rodovias estaduais e federais, instituições do Ensino superior, como a Universidade Federal de Santa Maria, a primeira universidade pública do interior do estado, implantada em 1960.

Em se tratando da Viação Férrea, o seu processo de implantação no município, começou em 1898, quando ocorreu o início dos trabalhos da Compagnie Auxiliaire, empresa belga, que passou a concentrar no mesmo, os seus escritórios administrativos, as principais oficinas de manutenção, assim como os depósitos de locomotivas e vagões, justamente por Santa Maria se situar numa região estratégica no entroncamento de linhas. Portanto, tal perspectiva implicou vincular a pesquisa junto a grupos de aposentados em espaços públicos no Centro da cidade, com a própria história social do município de Santa Maria.

Desde então, destaca o historiador João Rodolfho Amaral Flores (2007), a "cidade coração do Rio Grande”, passou a projetar-se no cenário regional, enquanto principal pólo ferroviário do estado, desencadeando um intenso fluxo de pessoas, o desenvolvimento do comércio local, a prestação de bens e serviços, e, inclusive, o aumento da população. ${ }^{4}$

\footnotetext{
${ }^{3}$ Informações extraídas do site do Instituto Brasileiro de Geografia e Estatística, www.ibge.go.br , em consulta realizada no dia 17/01/2010.

${ }^{4}$ Em 1920, a Viação Férrea, tornou-se autarquia do Estado, a VFRGS. Em 1957, passou ao domínio da União, quando da formação da Rede Ferroviária Federal Sociedade Anônima, a RFFSA, que fora privatizada na década de 1990 (Flôres, 2007). A grafia sobreposta VFRGS-RFFSA, utilizada ao longo do texto, visa contemplar os referidos períodos em que a viação férrea passou a ser gerenciada pelo governo estadual e federal, nas quais os interlocutores-personagens desse estudo antropológico trabalharam nessa instituição.
} 

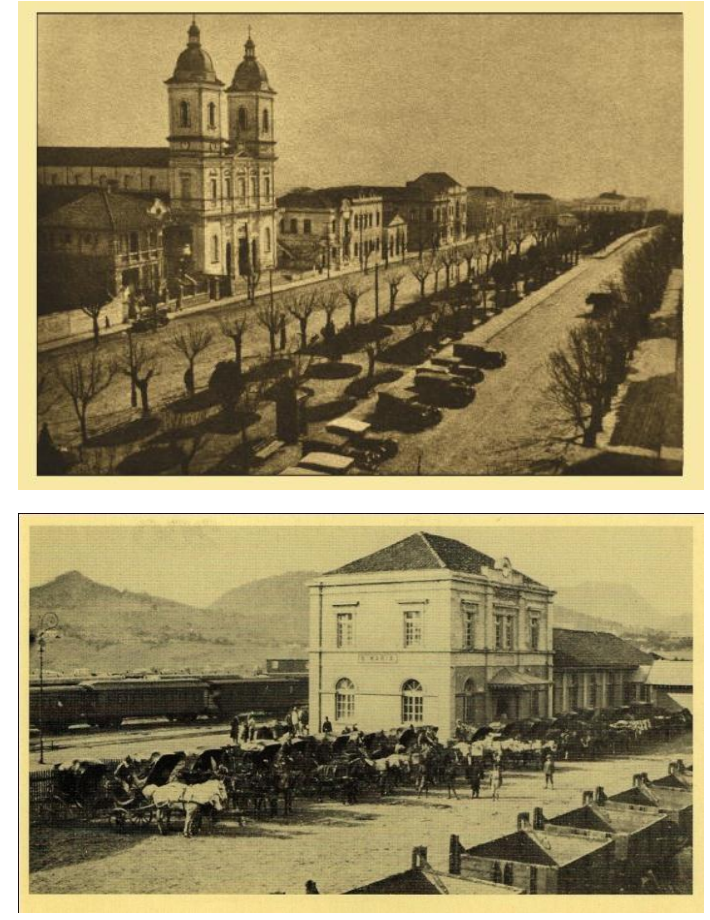

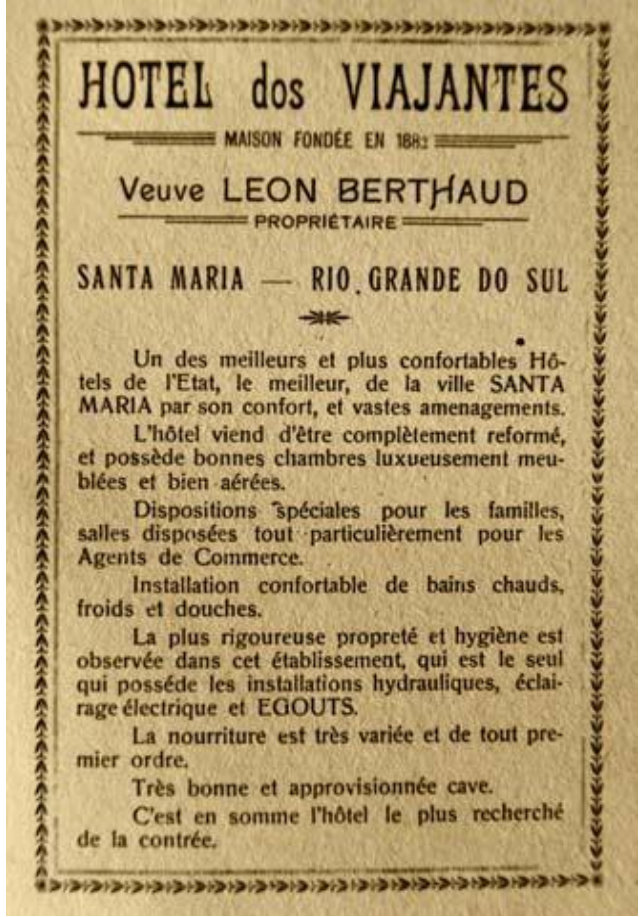

Im. 01- A “Avenida do Progresso” e a Igreja Matriz, em 1929. Im. 02 - Estação Ferroviária de Santa Maria, em 1914. Im. 03- A expansão da rede hoteleira: anúncio publicitário publicado em meados do século XX. In: MARCHIORI, José Newton Cardoso; FILHO, Valter Antônio Noal. Santa Maria - Relatos e impressões de viagem. Santa Maria: Ed. UFSM, 1997.

A presença cotidiana de aposentados no Centro da cidade, configurando territórios urbanos de sociabilidade nesse espaço urbano, oriundos de serviços públicos, tais como militares, professores, bancários, ferroviários, além de revelar diferentes formas de sociabilidade e uso do espaço urbano, revela algumas das implicações da conjuntura sóciohistórica referida anteriormente, na estética da vida urbana santamariense.

\section{Uma etnografia no Centro da cidade: mapeando territórios e identificando "interlocutores-personagens"}

Constatou-se através da "etnografia de rua", que para uma grande maioria dos citadinos, o Centro da cidade de Santa Maria, é configurado pelo Calçadão Salvador Isaia, composto por duas quadras da Rua Dr. Bozano, que abrigam, principalmente, casas e prédios comerciais, e, pela Praça Saldanha Marinho, que se une ao Calçadão através de um pequeno viaduto, construído na década de 1990 com o intuito de evitar o tráfego de automóveis nas proximidades desses espaços. 
As referidas intervenções urbanas foram evocadas nas narrativas de alguns aposentados habitués do Centro de Santa Maria, que foram os "interlocutores-personagens" dessa pesquisa etnográfica (Nunes, 2010). ${ }^{5}$

Ao narrar alguns aspectos da sua trajetória social e descrever o seu itinerário pelo Centro da cidade de Santa Maria para fins do seu trabalho, o santamariense Paulo Rodrigues, o Paulinho, como é popularmente conhecido, revendedor lotérico que possui 71 anos, realizou algumas considerações acerca desse espaço urbano:

"Quando eu nasci, os meus pais moravam no chamado Passo da Cancela, ali perto da Expresso Mercúrio. Ali, naquele tempo, era o Passo da cancela, mas hoje já falam na Vila Urlândia. Eu cresci ali, depois vinha vindo, vim pro Centro da cidade. E em 1958 eu me dediquei a venda de bilhetes e até hoje eu estou nesse ramo. Comprei o apartamento[no Centro] em 1984. Eu vim pra cá depois da "reforma do Banrisul". Eu andava mais pelos arredores do Centro e viajava por São Sepé, Caçapava e Cachoeira.

Depois as passagens foram aumentando e então eu deixei de viajar e vim pra cá, quando já era o banco reformado. Mas eu conheci o banco velho. Antes não tinha o túnel. Na avenida passavam os desfiles estudantis, militares e carnaval, em 1958, 1959, 1960...

Foi em 1959 que eu comecei a vender bilhetes, sempre ali pelo Centro. Mas mudou muito o Centro! O Calçadão não tinha, era rua, passava auto, ônibus. Chamavam de "primeira quadra". Quando terminavam os cinemas no final de semana, faziam ponto de encontro: as turmas de rapazes e moças. Principalmente as turmas de rapazes parados bem no meio, pra conversar e olhar para as meninas.

Naquele tempo tinha muito cinema. Era a primeira quadra. Depois que começou o Calçadão" (Entrevista, 28/09/2009).

\footnotetext{
${ }^{5} \mathrm{O}$ termo habitués refere-se aos freqüentadores habituais do Centro, em contrapartida aos freqüentadores ocasionais e esporádicos. Por sua vez, ao considerar esses habitués enquanto "interlocutores", pretendo estabelecer uma relação mais dialógica e simétrica no encontro e escrita etnográfica. Tendo em vista que o "antropólogo consiste em um narrador" (Eckert e Rocha, 2005), que narra a sua experiência e a do "outro" a partir do encontro etnográfico, e que a própria "etnografia é uma narrativa" (Bruner, 2006), também os considero enquanto "personagens". Daí o termo "interlocutores-personagens" (Nunes, 2010: 57).
} 

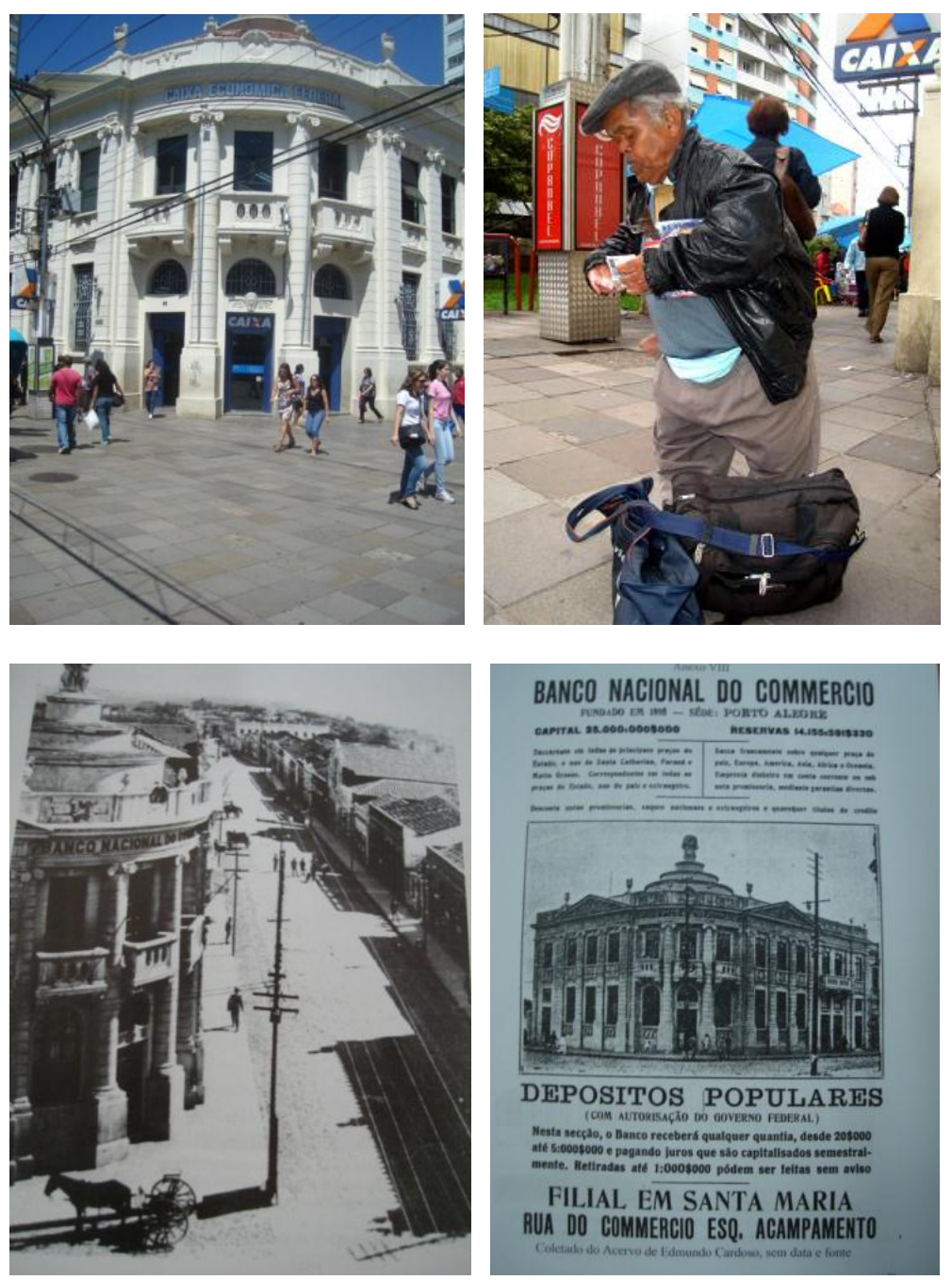

Im. 04 - Fachada do prédio da Caixa Econômica Federal, esq. da Rua do Acampamento com a Rua Dr. Bozano. Im.05- Paulinho e suas "artes de fazer", fotografias de Rojane Brum Nunes. Im. 06- Fachada do prédio do Banco Nacional do Comércio, esq. Rua do Acampamento com a Rua do Comércio, c/ vistas a sua "primeira quadra", década de 1920. Im.07 Anúncio publicitário do Banco Nacional do Comércio, 1918, fotografias do Arquivo Histórico Municipal.

Por sua vez, o ferroviário aposentado Zulmir Manfron, que nasceu e morou em Santa Maria, no bairro Itararé, até a década de 1970, destaca algumas das transformações urbanas com as quais se deparou no Centro da cidade, ao voltar a residir na mesma no ano de 1989:

"Naquele tempo não tinha camelódromo, não tinha nada ali [Centro] e agora tem de tudo! Naquele tempo a Praça ia até ali onde estão os camelôs... A gente sentava lá na beira. Antes dava para sentar ali, não tinha nem aquele viaduto. Quando eu saí daqui não tinha ainda. O viaduto eu acho que melhorou, senão, tu já pensou? Passando carro toda hora ali?" (Entrevista, 26/09/2009). 
Im. 08 - "Cartografia do Espaço", exercício realizado

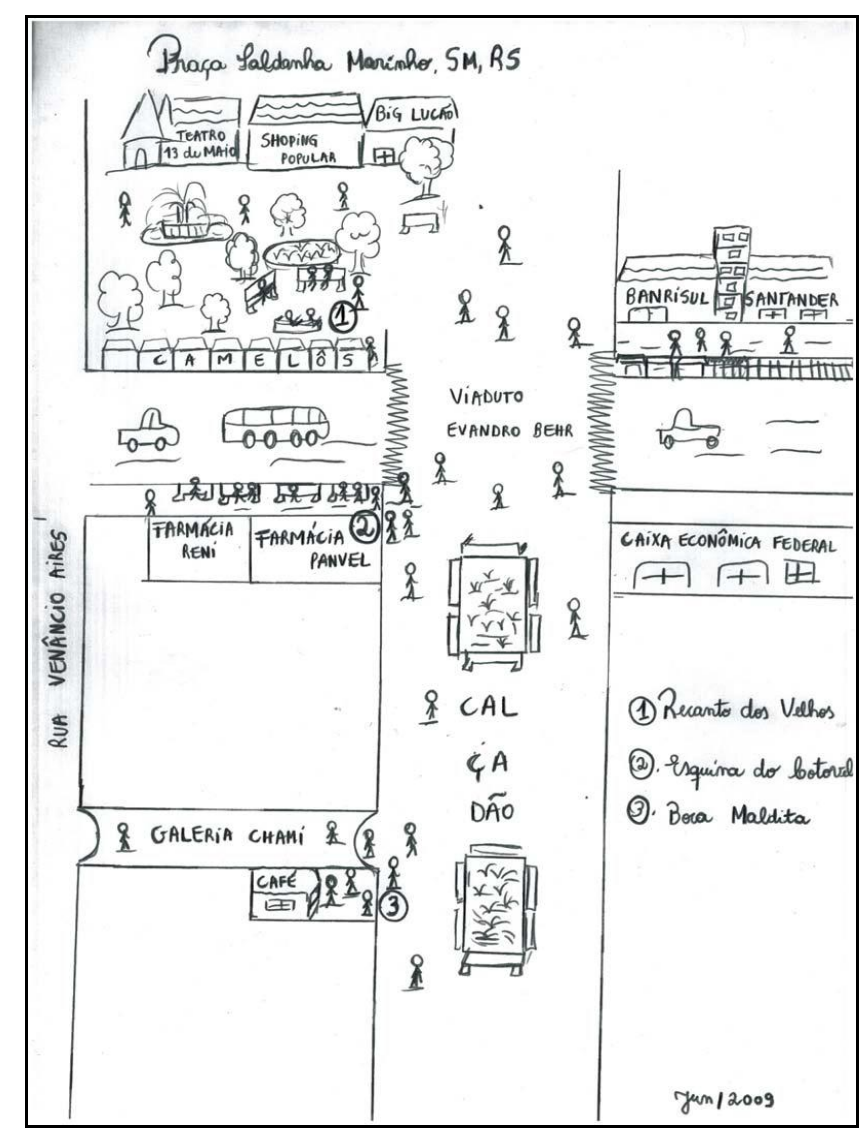

Através do deslocamento constante e sistemático pelo Centro da cidade de Santa Maria, com vistas à realização de uma "etnografia de rua", foi possível identificar e mapear alguns territórios de sociabilidade entre aposentados, configurados nesse espaço urbano. Entre esses territórios, encontram-se o Recanto dos Velhos, na Praça Saldanha Marinho, a Esquina do Cotovelo, em frente à farmácia Panvel, no Calçadão e a Boca Maldita, localizada na Galeria Chami, também no Calçadão.

Por outro lado, a "etnografia de rua" e o propósito de realizar uma "etnografia da duração", revelaram alguns dos habitués de cada um desses territórios, cujas narrativas biográficas, deslocamentos e itinerários urbanos, apreendidos através do trabalho de campo seguido de uma "descrição densa" (Geertz, 1979), possibilitaram a construção dos mesmos enquanto personagens da narrativa etnográfica.

Nesse particular, convém recordar Raul Diaz (1999), quando ao apropriar-se do legado teórico de Paul Ricouer, propõe uma mediação com a elaboração de descrições denominadas 
"si mesmos", destacando que "mediante elas provocamos a identidade narrativa que se expõe ao enunciar-se no ato discursivo, na medida em que a trama do 'si narrado' é retomado pelo nosso programa narrativo enquanto interpretantes daquele" (Diaz , 1999:37).

Nesse sentido, a recorrência à idéia de "sujeitos centrais" da problemática do "si mesmo" e da "identidade narrativa" (Ricoeur, 1991) tem por objetivo resgatar a maior singularidade com a qual os entrevistados interpretam a sua posição no mundo, a partir da introdução do tema-objeto por parte do pesquisador na atenção do antropólogo, através da sua escuta e interlocução. ${ }^{6}$

Os entrevistados, por sua vez, ao assumirem-se como sujeitos centrais do seu próprio discurso, constituem-se em "personagens" nessa situação dialógica, cujo enfoque destes $s i$ mesmos, engendram uma forma particular de narrativa, configurando uma "significação ética e política" construída "acerca de sua própria figura em alguns dos espaços sociais mencionados nessa comunicação" (Diaz, 1999:38).

A adesão às perspectivas teóricas revisitadas até então, implicou em algumas modificações na minha representação inicial do espaço, até então vista sobre o prisma de uma "cidade-panorama", que tende a desconsiderar as apropriações do espaço por parte dos "praticantes ordinários da cidade" através de suas diferentes "artes de fazer" e "reinventar o cotidiano" (De Certeau, 1994).

A seguir, uma nova "cartografia" do espaço, imagens empreendidas por mim, a partir da continuidade do trabalho de campo realizado no Centro da cidade de Santa Maria, para fins de exercício proposto na disciplina de Antropologia Visual, PPGAS/UFRGS, semestre 2009/01:

\footnotetext{
${ }^{6}$ Cabe aqui recordar o antropólogo Roberto Cardoso de Oliveira (2000) quando assinala que as habilidades de olhar, ouvir e escrever, caracterizam o trabalho do antropólogo.
} 

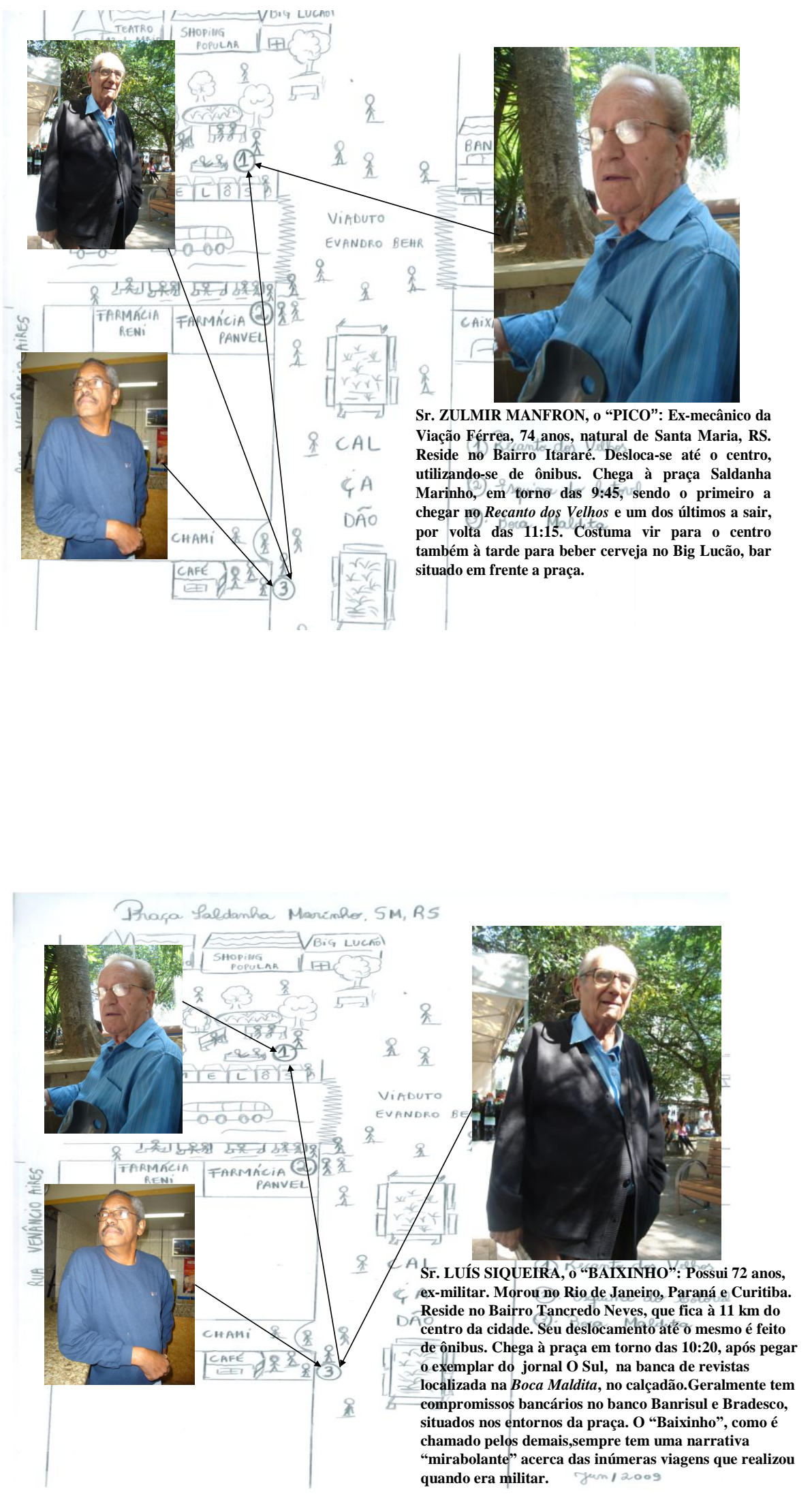


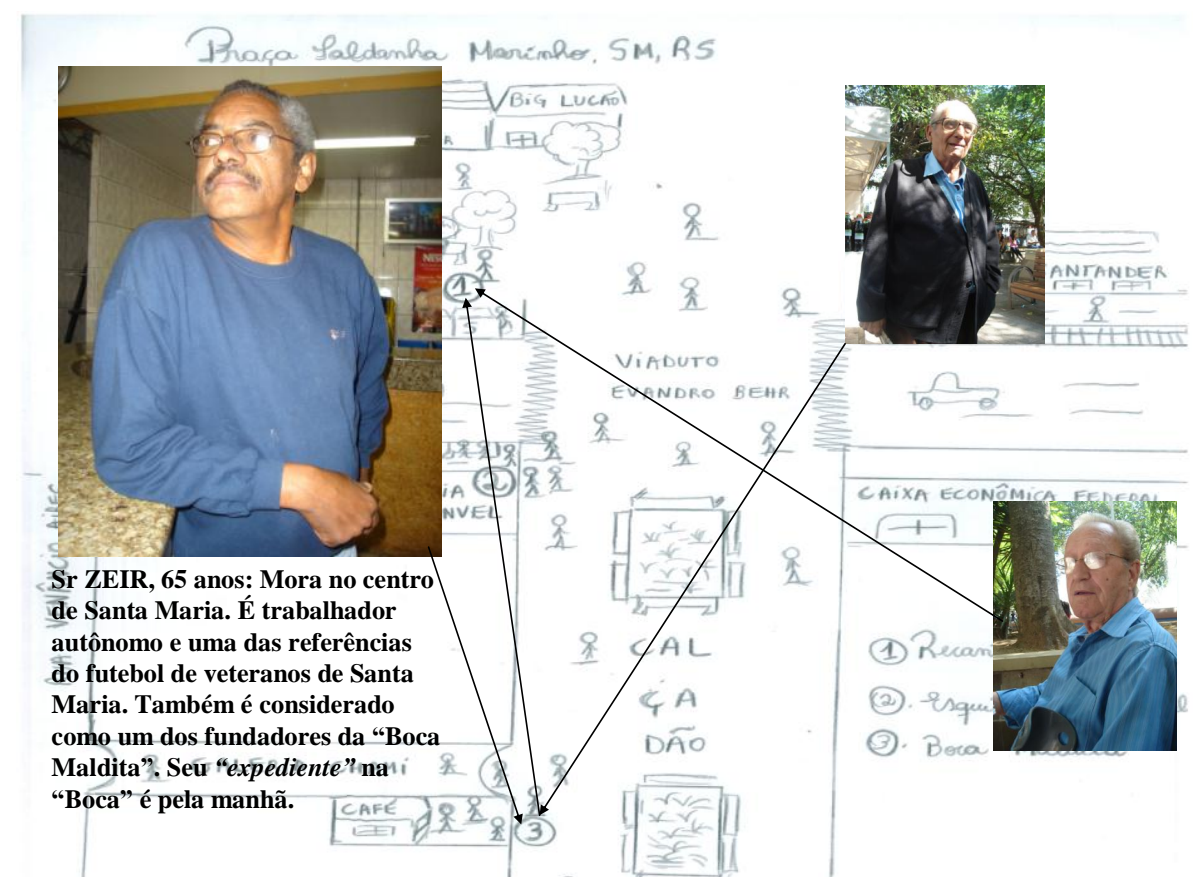

Tendo em vista as dimensões simbólicas que norteiam as formas de uso do espaço, e que ele existe para além da sua materialidade, faz-se necessário estabelecer um diálogo teórico com alguns dos autores que aderiram a essas dimensões que extrapolam o caráter meramente físico do espaço.

Nesse sentido, a análise dos espaços e dos campos sociais nos quais os agentes sociais se encontram inseridos a partir de seus diferentes capitais, empreendida por Pierre Bourdieu (1997), concebe o espaço social como uma realidade "estruturada e estruturante" que organiza as práticas e as representações dos agentes. Sob essa perspectiva, podemos pensar que tanto os espaços físicos quanto os espaços sociais são coexistentes tendo em vista que ambos “estruturam e são estruturados".

Por sua vez, Michel de Certeau (1994) considera que ato de caminhar, que desencadeia a apropriação do espaço, está para o sistema urbano assim como a enunciação está para a língua ou para os enunciados proferidos. A partir do conceito de "enunciação pedestre", esse autor considera que o espaço tem uma tríplice função "enunciativa": é um processo de apropriação do sistema topográfico pelo pedestre; é uma realização espacial do lugar e implica relações entre posições diferenciadas, ou seja, "contratos pragmáticos" sob a forma de movimentos (De Certeau, 1994:177). 
A pesquisa etnográfica realizada no Centro de Santa Maria, ao buscar apreender as peculiaridades e as complexidades dos grupos de aposentados, muitas vezes englobados/homogeneizados sob a categoria de "aposentados do centro", revelou, por sua vez, que os processos de territorialização do espaço urbano empreendidos pelos mesmos assumem diferentes feições, tal como veremos a seguir, ao discorrermos acerca do Recanto dos Velhos e da Esquina do Cotovelo.

\section{“A praça é nossa, mas aqui é o meu lugar": etnografando o (no) Recanto dos Velhos}

Em maio de 2008, me inseri junto a um grupo de aposentados que costuma sentar-se à sombra em alguns dos bancos da Praça Saldanha Marinho. Na ocasião, ao pedir licença para sentar-me entre eles, Zulmir Manfron, na época com 73 anos de idade, respondeu-me imediatamente: "pode sim, pois a praça é nossa como dizem, mas aqui é o meu lugar".

Logo a seguir, perguntei-lhes se durante o período de realização da Feira do Livro evento anual que ocorre na Praça no mês de maio - ficavam impossibilitados de permanecer na mesma. Luís, o Baixinho, respondeu-me, enfaticamente, enquanto gesticulava com as mãos apontando para os bancos onde estavam sentados:

“Não! Aqui no nosso quadrilátero, no nosso Recanto dos Velhos, eles não mexem! O Prefeito precisa de nós aqui, aquela pedra que estava ali adiante atrapalhando os pedestres, foi retirada porque nós avisamos a Prefeitura!' (Diário de Campo, 21/05/2008).

As considerações acima, realizadas para uma estranha ao grupo, uma “outsider", como sugerem Elias e Scotson (2000), além de revelarem o pertencimento desses atores sociais que os coloca na condição de "estabelecidos", demonstram a instabilidade do que Norbert Elias (1993) denomina de uma "balança nós-eu". 7

Diga-se de passagem, esse conceito auxilia-nos na análise das relações entre o indivíduo e a coletividade, as quais configuram a construção de uma subjetividade processual, através dos processos de "sociogênese" e "psicogênese", acomodando um "eu" a partir da condição de um "nós", e vice-versa.

Na medida em que a declaração de que a "praça é nossa" reclina para um "nós", que se configura pela condição de sermos cidadãos urbanos, a afirmação "aqui é o meu lugar" reclina para o "eu". Do mesmo modo, a "balança" tende para o "nós", quando destacam que "o prefeito precisa de nós aqui”, revelando o pertencimento a determinadas redes sociais,

\footnotetext{
${ }^{7}$ A partir de um estudo realizado em uma comunidade industrial urbana, Elias e Scotson (2000) sugerem as categorias analíticas "estabelecidos e outsiders" como instrumentos teóricos para analisar o jogo de poder que permeia as relações cotidianas entre os grupos sociais e indivíduos. No referido caso, os autores assinalam que a questão da temporalidade é central para definir quem são os que "pertencessem à comunidade" e os que estão fora da mesma, ou seja, os outsiders.
} 
engendradas ao longo das suas trajetórias sociais e (re)atualizadas através de suas formas de sociabilidade.

Pode-se dizer, que as presenças cotidianas desses aposentados no Centro da cidade, dinamizam um sistema de trocas e sociabilidades que permitem um jogo de reconhecimentos do "eu" e do "outro" em um "nós" que é a cidade, constituída pelos seus diferentes territórios. Assim não há estranhamento dos citadinos no espaço social em que circulam, na medida em que eles também "são" a cidade.
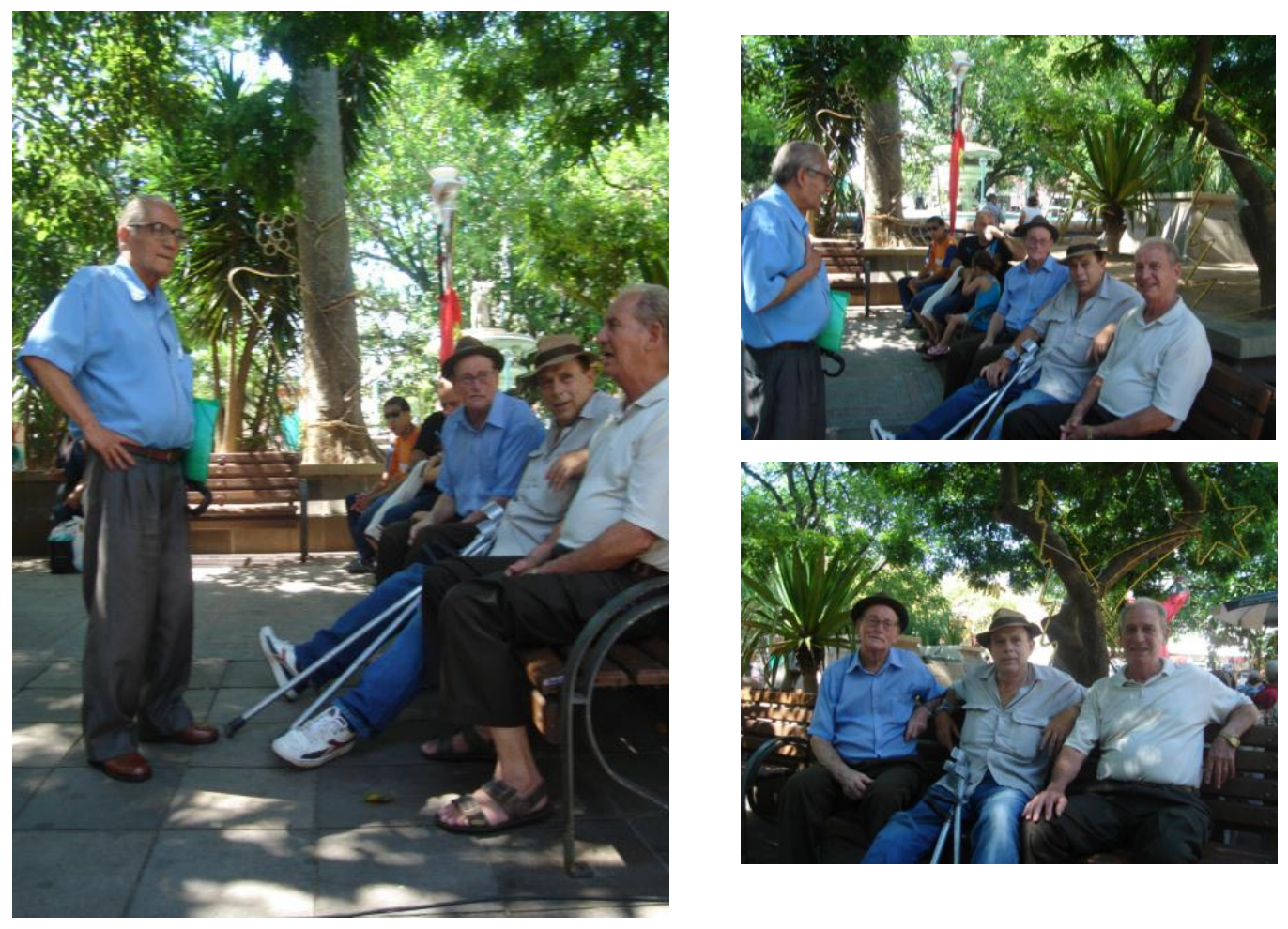

Im. 12,13 e 14 - "sociabilidade lúdica” no Recanto dos Velhos, fotografias de Rojane Brum Nunes.

A pesquisa etnográfica identificou que esse "nós" no qual consiste o Recanto dos Velhos, constitui-se por homens aposentados que se encontram na faixa dos 70 e 75 anos de idade, em sua maioria funcionários públicos aposentados da VFRGS-RFFSA e alguns do serviço militar, que se apropriam desse espaço público, principalmente no turno da manhã, entre 9 h30min e 11 horas. 
Constatou-se por outro lado, que o "rito de instituição" (Bourdieu, 2008) operado pelo processo de aposentadoria, não é algo recente em suas trajetórias sociais, tendo em vista que muitos deles aposentaram-se, por tempo de serviço, em torno dos 50 anos de idade.

Em uma situação de entrevista perguntei ao Luís, militar aposentado, habitué do Recanto dos velhos, de onde ele conhecia o Joaquim e o Zulmir, ambos ferroviários aposentados, também habitués desse território. A resposta que ele deu a minha pergunta foi a seguinte:

"Daqui da praça! Ficamos amigos aqui mesmo. Já demos muitas risadas por aqui! Mas, depois que soube que ele era colega do meu irmão lá na Rede [VFRGS-RFFSA], ficamos mais amigos ainda! Somos velhos amigos! E amigos velhos também [risos]. Mas, ele é muito mais velho do que eu, hein! [risos]" (Diário de Campo, 17/09/2009).

A referência ao parentesco de Luís, o "Baixinho" também apareceu na fala de Odon, que atuara no escritório da VFRGS-RFFSA, na cidade de Santa Maria:

"O Baixinho nós conhecemos lá da praça mesmo. Mas nós já conhecíamos o Adão, o irmão dele, que trabalhava lá na farmácia da cooperativa DA Rede [RFFSA]. Foi por aí que iniciamos a nossa conversa. Olha, vou te dizer uma coisa, quando tu enxergar um monte de ferroviário junto, já sabe: só o que falam é de salário, da aposentadoria, do Lula [Presidente da República] e da Ieda [Governadora do RS]!" (Diário de Campo, 26/07/2009).

Percebe-se, desse modo, a implicação da "Rede" na configuração das formas de sociabilidade dos habitués do Recanto dos Velhos. Nesse sentido, a "Rede" tal como se referem, é um espaço de trabalho que consiste em um "espaço-referência" e uma "imagemmemória" (Eckert, 1993) que configura redes sociais e engendra pertencimentos de ordem profissional e institucional, entre outros.

De acordo com Larissa Lommitz (1994), as redes sociais consistem em pequenas e complexas estruturas coletivas, que configuram redes de intercâmbios recíprocos, cujos fatores que ajudam a inibir ou implementar tais intercâmbios, são de caráter tanto objetivo quanto subjetivo, de modo que seus efeitos tendem a influenciar a formação ou desintegração das redes. 


\section{Ilustração gráfica de uma rede social}

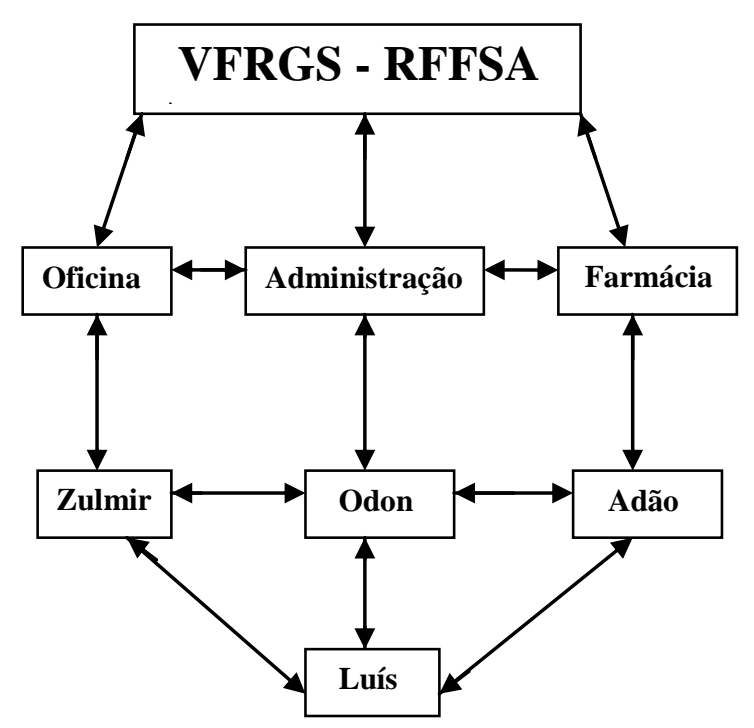

Im. 15: Exercício gráfico de redes sociais, PPGAS/UFRGS, disciplina de Metodologia sem $2 / 2008$.

Haja vista, as redes sociais configuradas pela viação férrea, assim como o jogo que ela suscita entre o individual e o coletivo, corroboram a afirmação de Maurice Halbwachs (2006), de que a memória é um fenômeno social e coletivo, implicado por determinados "quadros sociais de memória" pautados na noção de tempo e espaço.

Diga-se de passagem, é este autor que nos traz a dimensão da vida coletiva no cotidiano como uma amálgama de sentidos da trajetória de um grupo que compartilha de experiências e sentimentos comuns.

Para esses aposentados, o mundo do trabalho é agora vivido através do "tempo livre", do "tempo na praça" no qual tecem "sociabilidades lúdicas" e sistemas de reciprocidades que exigem o esforço rotineiro de "jogar o social” (Simmel, 1983). Nesse sentido, (re)constroem, através de suas práticas cotidianas, referências de pertença, (re)atualizando suas redes sociais e restabelecendo a continuidade no tempo, apesar das rupturas advindas do processo de aposentadoria, assim como da extinção material da VFRGS-RFFSA. Percebe-se tal busca, na declaração de Odon Shiling: orgulho de ser ferroviários.” (Diário de campo, 15/11/2009). 
Porém, apoiando-se em Gastón Bachelard (1994), compreende-se que as rupturas e as descontinuidades são condições necessárias à duração, na medida em que a memória é um espaço onde ocorre uma "fantástica transcendental" (Durand, 1997), um "reservatório dinâmico de símbolos e imagens" (Eckert e Rocha, 2005) coordenada no plano de uma imaginação criadora, cuja essência são as localizações espaciais e temporais.

Nesse sentido, os "jogos de memória" dos atores sociais em seus itinerários urbanos e na trama de suas relações cotidianas, lhes possibilitam a (re)construção de suas identidades sociais, dos seus pertencimentos e da duração no tempo social.

\section{A Esquina do cotovelo: entre cutucar e militar}

A Esquina do Cotovelo, localizada em frente à farmácia Panvel, no Calçadão, é um território de sociabilidade, que se configura, sobretudo, no período da tarde, cujos frequentadores são aposentados ferroviários, entre os 65 e 75 anos de idade, de modo que muitas vezes o mesmo fora referenciado como sendo a "esquina dos ferroviários", demonstrando desde já, o forte pertencimento dos seus habitués a essa categoria profissional.

A designação Esquina do Cotovelo, evocada tanto por eles quanto por outros citadinos, o que revela a presença da mesma na memória coletiva, refere-se a uma das práticas realizadas no âmbito desse território, qual seja, a de "cutucar o cotovelo do amigo quando as mulheres bonitas passam”, tal como declarou um dos seus habitués:

\footnotetext{
"Aqui é a esquina do cutuco, do cotovelo! Nós ferroviários aposentados ficamos sentados aqui, e quando passa uma mulher bonita, cutucamos com o cotovelo o colega que está ao lado. É por isso que chamam de Esquina do Cotovelo!"' (Diário de Campo, 06/05/2009).
}

Ao ouvir isso, Muller, que soube mais tarde, ser o presidente da Associação dos Ferroviários, embora demonstrando concordar com a declaração do colega, adverte que "não vinham ali pra esquina só pra isso", informando ainda que antes de virem para a Esquina, encontram-se na "associação", se informam sobre a situação da categoria, "tomam um cafezinho e depois sobem para o Centro".

Percebe-se desse modo, que uma outra prática delineia algumas das feições e particularidades desse território: a militância. Esta prática, ao aproximar-lhes da condição de “aposentados-militantes", denota em grande medida, os seus esforços para a manutenção de uma vida pública, cuja luta política consiste em um dos meios de se manterem ativos e elaborarem projetos para o futuro, tal como destaca Júlio Simões (2004). 
Desse modo, as práticas advindas da militância revelam que a forma de sociabilidade tecida por ferroviários aposentados, em uma determinada esquina da cidade, está para além da contemplação das "mulheres bonitas que passam".

Haja vista, através do trabalho de campo foi possível apreender parte do percurso percorrido pelas referidas "novidades, negócios de dinheiro e das coisas da justiça”. Essas informações chegavam até a "esquina", principalmente através dos "aposentados-militantes" (Simões, 2004), que por volta das 15 horas deslocavam-se da Associação dos Ferroviários até a Esquina do Cotovelo.
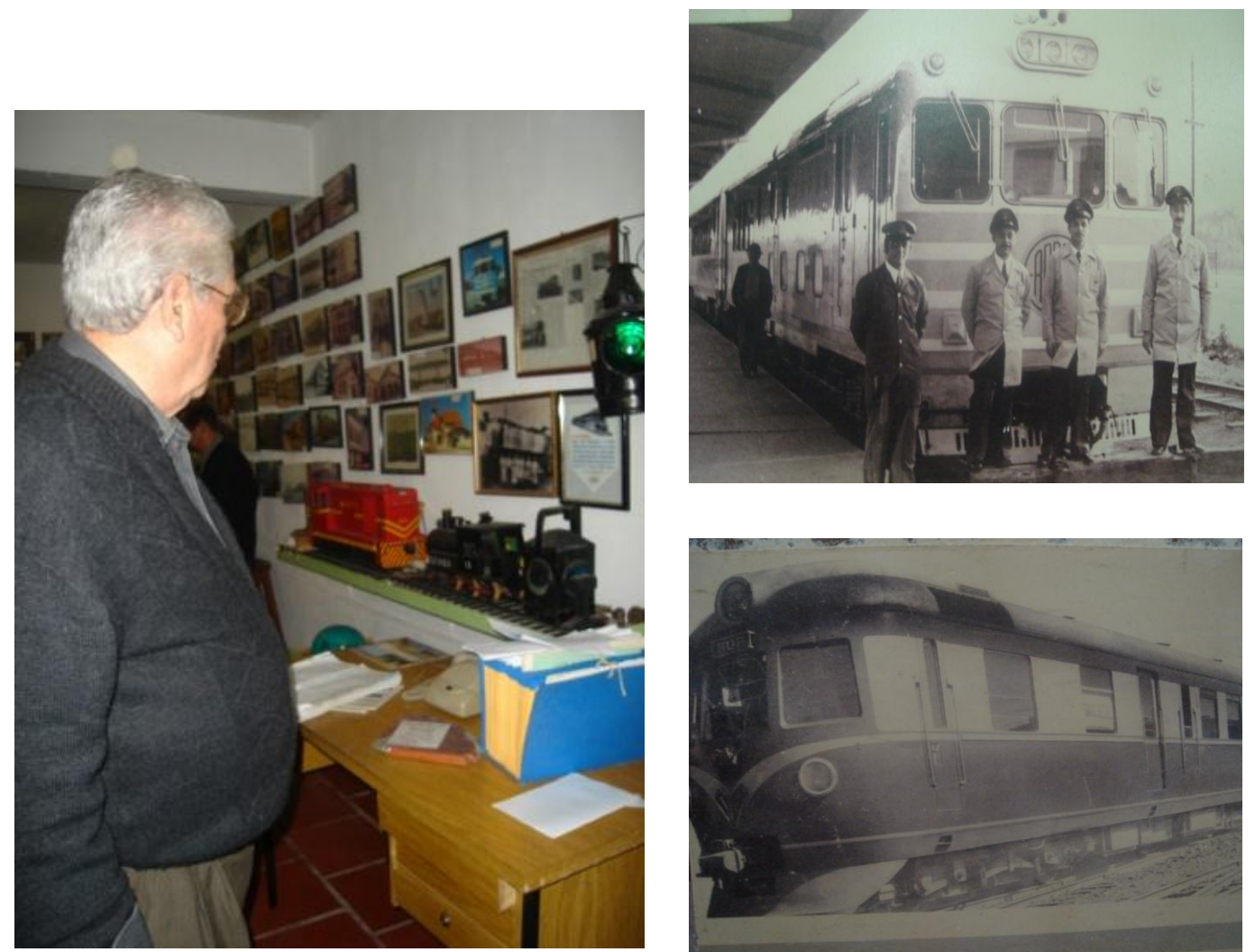

Im. 16 - "Um olhar 'sobre' os trilhos": Norberto Müller na Associação dos Ferroviários, fotografia de Rojane Brum Nunes. Im. 17: Trem Húngaro, 1974. Im. 18:: Trem Minuano, 1961, reproduções fotográficas de Rojane Brum Nunes do acervo fotográfico da Associação dos Aposentados Ferroviários de Santa Maria.

A referência à Esquina do Cotovelo como um lugar onde os ferroviários atualizam as notícias acerca dos processos jurídicos que envolvem a sua classe profissional, também apareceu no decorrer da entrevista que eu realizara com Zulmir, habitué do Recanto dos Velhos, que as vezes vai até a "esquina": 
“Eu 'subo' pro Centro para bater papo com a turma! Fazer o quê aqui no Centro? Comprar, não, porque eu não gosto da gastar! Venho pra bater papo com a turma, ficar ali no nosso recantinho... E também pra ficar por dentro, saber de alguma novidade, alguma coisa. Mas eu não sou muito curioso, tem cara que só vem aí pro Centro para saber negócio de dinheiro, se o governo pagou isso ou aquilo. Tem uma turma ali na 'esquina' que só vem pra isso: 'não tem nada novo? Não sabe se vai vir alguma coisa aí da justiça e tal?' Ainda hoje tinha um comentário lá,, que o governo ia pagar não sei o quê."(Entrevista, 24/11/2009).

Tal como Zulmir, o ferroviário aposentado Odon Shiling, também habitué do Recanto dos Velhos, costuma freqüentar a Esquina do Cotovelo:

“Ali na esquina é o segundo estágio. De manhã, eu subo pro Centro, lá pro Recanto, na Praça. É mais calmo, tem mais árvores. E de tarde, dou uma passadinha na Esquina do cutuco" pra saber das 'novas' que têm para os ferroviários" (Diário de Campo, 26/09/2009).

Verifica-se nesse sentido, que os "limiares de sociabilidade" são transpostos na medida em que os aposentados habitués do Recanto dos Velhos, interagem com aqueles da Esquina do Cotovelo, "motivados por propósitos e conteúdos objetivos, e, quando seus aspectos subjetivos e pessoais se fazem sentir" (Simmel, 1983:171).

Por outro lado, os deslocamentos dos aposentados por entre os diferentes territórios de sociabilidade, apreendidos através de um "olhar descentralizado, em movimento, para fazer também nomadizar o esforço da investigação" (Diógenes, 1998:56), revelam que os mesmos não consistem em unidades territoriais estáticas, mas sim em lócus que expressam o dinamismo das diferentes instâncias de sociabilidade.

Diga-se de passagem, esse caráter dinâmico das interações sociais, demonstra que os sistemas de reciprocidades tecidos entre os grupos e indivíduos, através das suas inserções em redes sociais, implicam na construção de alianças temporárias, colocando-os na condição de empreendedores sociais (Boissevain, 1987).

Em se tratando dos possíveis conflitos desencadeados nas diferentes formas de sociabilidade, Simmel (1983) assinala que este possui uma significativa importância sociológica, consistindo em um elemento da própria relação, e, portanto numa "forma de sociação" que se estabelece entre os grupos e os indivíduos.

Para o sociólogo, a própria sociedade refere-se à interação social, a qual surge a partir de certos impulsos ou em função de certos propósitos. Desse modo, tudo o que estiver presente nos indivíduos sob a forma de impulso, interesse ou estado psíquico, engendrando ou mediando influências sobre os outros, são designadas por esse autor enquanto "conteúdo da sociação" (Simmel, 1983).

Pode-se dizer que o propósito dos ferroviários aposentados em atualizarem-se acerca de processos jurídicos da categoria, através de “um bate-papo na Esquina do Cotovelo”, 
demonstra que o mesmo consiste em um dos conteúdos que tecem uma forma específica de "sociabilidade lúdica" em uma das esquinas da cidade.

Por outro lado, verificam-se as implicações dos "tempos da Rede" [RFFSA] a essa forma de sociabilidade, cuja manutenção de vínculos com a mesma, através de causas jurídicas contra o poder público, consiste estratégia de restabelecer a continuidade no tempo social, (re)afirmando o pertencimento a uma categoria profissional e possibilitando a manutenção de redes sociais configuradas pelo mundo do trabalho.

Nesse sentido, a capacidade de "restauro" dos tempos vividos, dada pelo caráter interpretativo dos "jogos de memória", possibilita aos habitués da Esquina do Cotovelo e do Recanto dos Velhos, (re)atualizarem a condição de "ser ferroviário", através do pertencimento a uma "comunidade de trabalho", permitindo-lhes o devaneio do tempo vivido como contínuo, inscrevendo no Centro da cidade formas particulares de "enunciação pedestre", como sugere Michel De Certeau.

Muitas vezes me perguntara se caso a ferrovia ainda existisse, esses encontros com os ex-colegas ocorreriam, sendo que a resposta a essa inquietação remeteu-me aos estudos de Cornelia Eckert e Ana Luiza C. da Rocha (2005) acerca de Gastón Bachelard, nos quais considera-se que as rupturas e as descontinuidades são condições necessárias à duração social.

Nesse sentido, a memória é concebida por essas antropólogas como um "espaço fantástico", um lócus de extroversão/introversão de uma linguagem convencional de símbolos, coordenada no plano de uma "imaginação criadora", tendo como essência as localizações espaciais e temporais.

Sob essa perspectiva, a memória, enquanto o espaço onde ocorre uma "fantástica transcendental" e o reservatório dinâmico de símbolos e imagens, é o fenômeno que permite através dos "jogos de memória" dos atores sociais em seus itinerários urbanos e na trama de suas redes de relações cotidianas, a (re)construção de suas identidades sociais.

Ao revisitar a Esquina do Cotovelo e o "sindicato", no período final da escrita da dissertação, informo-lhes que no capítulo em que discorro sobre o referido território urbano, refiro-me ao mesmo enquanto a Esquina do Cotovelo, cujos freqüentadores assíduos são ferroviários aposentados. Após esse comentário, o silêncio que pairou no ar, imediatamente levou-me a pensar não que haviam gostado de tal referência.

Enquanto eu pensava em como contornar a situação, Lucindo Minato, 74 anos, corrige o nome dizendo-me em tom jocoso e veemente: “opa! Esquina, não! É a quadra do cotovelo! Olha o monte de bancos que tem aqui, é quase uma quadra! E cheia de ferroviários! [risos]". 
A jocosa "correção", além de denunciar que o silêncio fora proposital, demonstrou, mais uma vez, que os habitués da Esquina do Cotovelo sentem orgulho em freqüentá-la, inscrevendo no Centro da cidade uma forma particular de "enunciação pedestre" (De Certeau, 1994), fortemente associada a uma categoria profissional.

Constatou-se a partir da pesquisa etnográfica, que os aposentados habitués do Recanto dos Velhos e da Esquina do Cotovelo, percebem-se, sobretudo, enquanto "ferroviários aposentados", e não enquanto "ex-ferroviários", como eu mesma muitas vezes me referi aos mesmos. Nesse sentido, não deixam de ser ferroviários apesar de estarem aposentados, o que demonstra o esforço que empreendem na trama de suas relações cotidianas a fim de restabelecerem a continuidade, apesar da descontinuidade instaurada pelo processo da aposentadoria e da extinção material da ferrovia.

Diga-se de passagem, a aposentadoria, além de mostrar-se como um "rito de instituição que instaura a diferença" (Bourdieu, 2008), consiste em um "campo de possibilidades" (Velho, 2003) que permite novos ritmos às suas práticas cotidianas, através das quais (re)atualizam as suas redes sociais de pertença, tecendo formas específicas de sociabilidade lúdica e delineando a duração, diante de um tempo descontínuo e lacunar.

\section{Territórios urbanos, redes sociais e memória coletiva}

O estudo antropológico realizado no Centro da cidade de Santa Maria, acerca das diferentes formas de apropriação do espaço urbano, remete-nos às noções de "diferença" e/ou "diversidade", que por sua vez, atrelam-se a um dos conceitos fundantes da Antropologia, qual seja, o conceito de cultura.

Entre as problematizações teóricas acerca das noções de "diferença" e "diversidade", encontram-se aquelas propostas pelo antropólogo pós-colonialista Homi Bhabha (1998) quando assinala o caráter reificador do conceito de "diversidade cultural".

Esse conceito, segundo o autor, traz uma representação da diferença a partir de traços culturais herdados e transmissíveis que constituem um sistema estável de diferenças, de modo que a noção de "diferença" compreende "os modos de enunciação" e a constante produção de novas significações por parte dos atores sociais.

Sob essa perspectiva, podemos considerar que os distintos processos de territorialização de espaços urbanos no Centro da cidade, por parte de grupos de aposentados em interações e sociabilidades, consistem em "modos de enunciação" da diferença.

Por outro lado, o diálogo teórico com diferentes autores, a partir das suas definições ao conceito de cultura, torna-se imprescindível, na medida em que contribuem sobremaneira para 
nortear a prática de pesquisa antropológica e a reflexão acerca de nossos pressupostos teóricos, metodológicos e epistemológicos.

Porém, ao tomarmos essas definições conceituais - mais complementares que excludentes - enquanto instrumentos teóricos que nos auxiliam na compreensão dos constantes processos de (re)significações que os atores sociais produzem, percebemos que o conceito de cultura mostra-se, sobretudo, enquanto um conceito operacional, na medida que ele não consiste em um fim em si mesmo, mas, em um meio pelo qual se opera o fazer antropológico.

A cultura de acordo com o antropólogo Clifford Geertz (1989) consiste em uma "teia de significados" e "um mecanismo de controle", sendo que para Marshall Sahlins (1987) ela equivale a "uma estrutura de longa duração". Por sua vez, Roy Wagner (1981) considera o conceito de cultura como uma "invenção ocidental", de modo que a relação comparativa, efetuada pelo antropólogo, através do "contraste experienciado" no encontro etnográfico é que permite ao mesmo criar e inventar "a sua cultura" e a do "outro", de modo que a relação seja fundamental para que ocorra a referida "invenção".

Por outro lado, James Clifford (1988) concebe a cultura como "contestação", na medida em que é necessário contestar as culturas, a fim de dissolver a sua suposta unidade e reificação, possibilitando que se reinventem, de modo que qualquer tentativa de demarcação é "anticontestação".

Os estudos de Eckert e Rocha (2005) sobre memória coletiva em contextos urbanos, deixam-nos por sua vez, o legado de que a cultura é, sobretudo, perpassada pelas relações que os atores sociais estabelecem com o tempo vivido e pensado, ou seja, pelas suas experiências temporais, desvelando a importância dos estudos sobre memória coletiva.

Nesse sentido, considera-se a memória como sendo o fluxo do tempo, o qual, de acordo com Gastón Bachelard (1994) é descontínuo e lacunar, implicando aos grupos e indivíduos o restabelecimento da continuidade face as incessantes rupturas temporais. Diga-se de passagem, a memória não consiste apenas em uma rememoração do passado, mas, sobretudo, num processo de (re)interpretação e redenção (Benjamin, 1983), no qual o passado, o presente e o devir encontram-se em constante sobreposição.

Compreende-se, sob essa perspectiva, a importância das práticas cotidianas, das formas de sociabilidade, do estabelecimento e manutenção das redes sociais de pertença, para que os grupos e indivíduos, em seus diferentes territórios, (re) instaurem a duração através da “fantástica transcendental”, na qual se situa o fenômeno da memória coletiva. 
Diga-se de passagem, o cotidiano, de acordo com Berger e Luckmann (1983), corresponde ao lugar da experiência que permite ao sujeito deslocar-se no tempo, (re)construindo sentidos, configurando "províncias de significado" e atualizando o seu "estoque social de conhecimentos" (Schutz, 1979) através da sua inserção em redes sociais diversas.

A cidade, desse modo, transcende a condição de algo externo, enquanto um conceito meramente teórico ou panorâmico, consistindo em um "objeto temporal" que se (re)inventa a partir das diferentes memórias e trajetórias dos seus habitantes, traduzindo-se como um contexto constantemente (re)configurado pelo fenômeno da memória coletiva.

A partir da pesquisa etnográfica realizada no Centro de Santa Maria, infere-se que esta cidade se traduz na memória dos aposentados, de modo que eles também são a cidade, no espaço e no tempo, tendo em vista que ela consiste em um território que expressa as suas as suas experiências temporais, (re)configurando as suas identidades e pertencimentos em uma temporalidade específica de suas vidas.

\section{Referências}

BACHELARD, Gaston. A dialética da duração. São Paulo: Ática, 1994.

BENJAMIN, Walter. "Sobre alguns temas em Baudelaire". In: Charles Baudelaire: um lírico no auge do capitalismo. São Paulo: Brasiliense, 1989. p.103-149.

BERGER, Peter, LUCKMANN, Thomas. A construção social da realidade. Petrópolis: Vozes, 1983.

BHABHA, Homi. O local da cultura. Belo Horizonte: Editora UFMG, 1998.

BOURDIEU, Pierre (Coord). "Efeitos de lugar". In: A miséria do mundo. Petrópolis: Vozes, 1997. p.160-166.

BOURDIEU, Pierre. A distinção. Crítica social do julgamento. Porto Alegre: Zouk, 2008.

BOISSEVAIN, Jeremy. "Apresentando 'amigos de amigos: redes sociais, manipuladores e coalizões"'. In: FELDMAN-BIANCO, Bela (Org). Antropologia das sociedades contemporâneas - métodos. São Paulo: Global Universitária, 1987. Parte II.

BRUNER, Edward M. "Ethnography as narrative". In: TURNER, Victor e BRUNER, Edward (Eds.). The Anthropology of experience. Chicago: University of Illinois Press, 1986. p. 139155.

CLIFFORD, James. "Sobre a autoridade etnográfica". In: GONÇALVES, José Reginaldo S. (Org.). A experiência etnográfica: antropologia e literatura no século XX. Rio de Janeiro: Editora UFRJ, 1998. p. 25-43.

CARDOSO DE OLIVEIRA, Roberto. O trabalho do antropólogo: olhar, ouvir, escrever. São Paulo: UNESP, 2000.

DE CERTEAU, Michel. A invenção do cotidiano: artes de fazer. Petrópolis: Vozes, 1994. DIAZ, Raul. "Personaje e identidad narrativa: una aproximacion metodológica". In: Revista Horizontes Antropologicos, $\mathrm{n}^{\circ} 12$. Porto Alegre: PPGAS - UFRGS, 1999. p. 37-58.

DURAND, Gilbert. As Estruturas Antropológicas do Imaginário. Lisboa: Presença, 1997. 
ECKERT, Cornelia. "Memória e Identidade. Ritmos e ressonâncias da duração de uma pequena comunidade de trabalho: mineiros do carvão - La Grand-Combe, França". In: Cadernos de Antropologia, n 11. Porto Alegre: Ed. UFRGS, 1993.

ECKERT, Cornelia, ROCHA, Ana Luiza Carvalho da. "Premissas para o estudo da memória coletiva no mundo urbano contemporâneo sob a ótica dos itinerários de grupos urbanos e suas formas de sociabilidade”. In: Revista Margem. São Paulo: PUC, 1998. p. 243-259.

ECKERT, Cornelia, ROCHA, Ana Luiza Carvalho da. O tempo e a cidade. Porto Alegre: Editora UFRGS, 2005.

ECKERT, Cornelia, ROCHA, Ana Luiza Carvalho da. "Memória e ritmos temporais: o pluralismo coerente da duração no interior das dinâmicas da cultura urbano-contemporânea." In: Estudos históricos, vol. 23, n. 43, janeiro-junho. Rio de Janeiro: Centro de Pesquisa e Documentação de História Contemporânea do Brasil - CPDOC/FGV, 2009. p. 105-124.

ELIAS, Norbert. A Sociedade dos Indivíduos. Lisboa: Dom Quixote, 1993.

ELIAS, Norbert. O processo civilizador. Rio de Janeiro: Jorge Zahar, 1994.

ELIAS, Norbert, SCOTSON, John. Os estabelecidos e os Outsiders. Sociologia das relações de poder a partir de uma pequena comunidade. Rio de Janeiro: Zahar, 2000.

FLÔRES, João Rodolfho Amaral. Fragmentos da história da Viação Férrea brasileira. Santa Maria: Pallotti, 2007.

GEERTZ, Clifford. A Interpretação das Culturas. Rio de Janeiro: LTC, 1989.

GOFFMANN, Erving. "Les Représentations". In: La mise en scène de la vie quotidienne. La présentation de Soi. Paris: Minuit, 1973. p. 25-77.

HALBWACHS, Maurice. A Memória Coletiva. São Paulo: Centauro, 2006.

LOMNITZ, Larissa. "Redes informales de intercambio en sistemas formales: un modelo teórico". In: Redes sociales cultura y poder: ensayos de antropologia latinoamericana. Mexico: Flacso, 1994. p 19-46.

NUNES, Rojane Brum. 'A 'Boca', a 'Esquina' e o 'Recanto': sociabilidade, cotidiano e memória entre aposentados habitués do Centro de Santa Maria, RS, Brasil". Porto Alegre: Programa de Pós-graduação em Antropologia Social, PPGAS/ UFRGS, (Dissertação de Mestrado), 2010.

PEIRANO, Mariza. "O encontro etnográfico e o dialogo teórico". In: Uma antropologia no plural. Três experiências contemporâneas. Brasília: Editora UNB, 1991. p. 132-142.

RICOEUR, Paul. Sí mismo como outro. México: Siglo XXI, 1991.

SAHLINS, Marshall. Ilhas de História. Rio de Janeiro: Jorge Zahar, 1987.

SCHUTZ, Alfred. 1979. "Ação no mundo da vida". In: WAGNER, Helmut R. (Org. e introdução). Fenomenologia e relações sociais. Textos escolhidos de Alfred Shutz. Rio de Janeiro: Zahar, 1979. p. 123-156.

SIMMEL, George. "Sociabilidade: um exemplo de sociologia pura ou formal". In: MORAES FILHO, Evaristo (Org.). Simmel. São Paulo: Ática, 1983. p. 165-181.

SIMÕES, Júlio Assis. "Provedores e militantes: imagens de homens aposentados na família e na vida pública”. In: PEIXOTO, Clarice Ehlers (Org.). Família e envelhecimento. Rio de Janeiro: Editora FGV, 2004. p.29-54.

VELHO, Gilberto."O antropólogo pesquisando a sua própria cidade: sobre conhecimento e heresia". In: O desafio da cidade: novas perspectivas sobre a Antropologia brasileira. Rio de Janeiro: Editora Campus, 1994. p. 13-20.

VELHO, Gilberto. Projeto e metamorfose. Antropologia das sociedades complexas. Rio de Janeiro: Jorge Zahar, 2003.

WAGNER, Roy. The invention of culture. Chicago: The University of Chicago Press, 1981. 